\title{
UYGUR HALK MIZAHINDA ANLATMALIK TÜRLER VE İCRACILARI
}

\author{
[Araştırma Makalesi / ResearchArticle]
}

Tugba GÖNEL SÖNMEZ *

GelişTarihi: 15.05.2020

Kabul Tarihi: 29.05.2020

$\ddot{O} z$

Mizah, hayatın gülünç ve anlamsız taraflarını değerlendirip sergileyebilme yetisidir, insana özgü olmakla birlikte toplumsal bir olgu olarak bilișsel, duyușsal ve davranışsal özellikler gösterir. Toplumdaki uyumsuzlukları, salt yıkıcllıktan ziyade ince bir nükte ve iyileştirici bir söylemle ortaya çıkarmaktadır. Toplumların mensup olduğu birçok değişkene (dil, din, coğrafya, iklim, kültür vb.) bağlı olarak farklılık gösteren ve karaktere bürünen mizah, sözlü, yazılı ve görsel olarak bünyesinde birç̧ok tür barındırmaktadır. Her türlü toplumsal ve ideolojik temanın ișlenebildiği mizah türleri aynı zamanda birey-toplum ve birey-birey ilişkisini diri tutan hassasiyetlerin de ele alınabilmesine olanak sağlamaktadır.

Çalışmada örnek metinlerden hareketle Uygur halk mizahı içerisinde sözlü yaratım ve aktarımdan beslenen latife, çakçak, yumur, laf, kızık ve kikas gibi anlatmalık türler ele alınmıs olup Uygur halk mizahı içerisinde ön plana çıkan Nasreddin Ependi, Seley Çakkan, Molla Zeydin ve Hisam Kurban gibi mizah icracıları tanitılıp değerlendirilmekte ve işlevleri ele alınmaktadır. Ayrıca Uygur toplumunun kolektif belleğinde nesilden nesle aktarılan mizah icracıları ve biyografilerine dikkat çekilmeye çalışılmaktadır.

Anahtar Kelimeler: Uygur Halk Mizahı, Latife, Çakçak, Yumur, Laf.

\section{NARRATIVE GENRES IN UYGHUR FOLK HUMOR AND THEIR PERFORMERS}

\begin{abstract}
Humor is the ability to evaluate and display the ridiculous and meaningless aspects of life, as it is unique to human, it shows cognitive, affective and behavioral features as a social phenomenon. It reveals incompatibilities in society with a subtle nuclear and healing discourse rather than mere destructiveness. The humor, which varies depending on the many variables (language, religion, geography, climate, culture ... etc) and which takes on the character, contains many genres in oral, written and visual form. The types of humor, in which all kinds of social and ideological themes can be processed, also enable the sensitivity to keep the individual-society and individual-individual relationship alive.

In the study, based on the sample texts, the narrative genres such as latife, çakçak, yumur, laf, kızık ve kikas; humor performers such as Nasreddin Ependi, Seley Çakkan, Molla Zeydin ve Hisam Kurban which are fed by verbal creation and transfer in Uyghur folk humor, are introduced and evaluated and their functions are discussed. In addition, it is tried to draw attention to the humor performers and biographies of the Uyghur society that are passed down from generation to generation in the collective memory.
\end{abstract}

Keywords: Uyghur Folk Humor, Latife, Çakçak, Yumur, Laf.

*Dr. Öğr. Üyesi, Nevşehir Hacı Bektaş Veli Üniversitesi, Fen Edebiyat Fakültesi, Türk Halk Bilimi Bölümü, e-posta: tugbagonelsonmez@gmail.com Orcid: 0000-0002-3858-887X 


\section{Giriş}

Gülme, toplumun aynı paydada buluştuğu bir duygu ve bu duygunun dişavurum şeklidir. Nitekim bir toplumun mizahını kavramak için o toplumun kültürel kodlarına hâkim olmak gerekir.

Mizah, Türkçe Sözlükte "gülmece" (1998: 1572); gülmece ise "eğlendirmek, güldürmek ve birinin, bir davranışa incitmeden takılmak amacını güden ince alay, mizah, humor (1998: 903) şeklinde tanımlanmaktadır. Mizah kavramının içerisinde fıkra, alay, latife, nükte, hiciv, hezliyyat, zevkiyyat, mutâyebat ve şathiyyat gibi birçok tür mevcuttur (Güvemli, 1949:3). Bireysel zekâ ve algılamanın yanı sıra söz konusu toplumun mensup olduğu din, dil, coğrafya ve iklim gibi birçok etmene bağlı olarak değiş̧kenlik gösteren mizahın işlevi, kökeni ve yapısı üzerine birçok teori bulunmaktadır. Bu teoriler genellikle üstünlük (superiority), uyuşmazlık (incongruity) ve rahatlama (relief) ${ }^{1}$ bağlamında tasnif edilmektedir.

Tenkit etme, düşündürme, eğlendirme, dikkat çekme, eğitme, şaşırtma ve aslî olarak güldürme işlevlerine sahip olan mizah, Uygur Türklerinde de birçok türü bünyesinde barındırmaktadır. Çalışmamızda, örnek metinlerden hareketle Uygur halk mizahı içerisinde bulunan türler tanıtılıp değerlendirilmiş ve işlevleri ele alınmıștır. Ayrıca Uygur toplumunun kolektif belleğinde nesilden nesle aktarılan mizah icracıları ve biyografilerine dikkat çekilmeye çalışılmıştır.

\section{Latife}

Uygur Türkçesinde çeşitli vakalar hakkında anlatılan komik, küçük hikâyeler olarak tanımlanan latifeler, Uygur halk edebiyatının anonim türlerinden olup halkın bilgeliği, gözlem gücü ve ileri görüşlülügünün ürünü olarak nükteli yapısı vasıtasıyla toplumdaki aksaklıklara dikkat çekmektedir (UTİL, 1994: 913; Zeyidi ve Dugayli, 1988: 298). Latifeler, asıl kahramanı insan olan, güçlü hicvi karaktere sahip, kısa soluklu ve tek bir vaka etrafında teşekkül eden sözlü kültür ürünleridir. Mizahın ve komedinin estetiğinden faydalanarak toplumdaki çeşitli aksaklıklara dikkat çeken latifeler, bu eleştirel bakış açısıyla diğer mizah türlerinden ayrılmaktadır. Ayrıca latifeler, sözlü kültür ürünü olmasının yanı sıra tarihi şahsiyetler etrafında teşekkül eden anekdotları da ihtiva edebilmesi sebebiyle halk hafızasında çeşitlenebilmektedirler (Tarim, 2009: 368; İsmayil, 1994: 172).

\subsection{Nasreddin Ependi}

Uygur latifeleri, genellikle Nasreddin Hoca etrafında teşekkül etmesi sebebiyle halk arasında "Ependi Latipiliri" olarak da bilinmektedir (Tarim, 2009: 368; İsmayil, 1994: 172). Nasreddin Efendi latifeleri, Orta Asya, Orta ve Yakın Doğu ve Arap coğrafyasına kadar geniş bir alanda anlatılıp yaşatılmaktadır (Tarim, 2009: 370). Nasreddin Hoca latifelerinin bu kadar geniş bir coğrafyaya yayılması Nasreddin Hoca'nın gerçek tarihi şahsiyeti ve latifelerin hepsinin kendisine aidiyeti hakkında birtakım soruları da beraberinde getirmektedir. ${ }^{2}$ Bu konuda Uygur Türkleri arasında farklı rivayetler mevcut olup Uygurca kaynaklarda Nasreddin Hoca'nın hayatı hakkında şu bilgilere yer verilmektedir:

Nasreddin Ependi, 1208 yılında Akşehir Hortu'da dünyaya gelmiştir. Sivrihisar'da medrese tahsili görmüş ve Hortu'da imamlık yapmıştır. Medrese tahsiline Konya'da devam etmiş olup 1237'de Akşehir Camisinde müderrislik yapmıştır. 1284 yılında Akşehir'de vefat etmiş ve burada defnedilmiştir (Tarim, 2009: 369).

Nasreddin Ependi, vefatının ardından da halk hafızasında yaşamaya devam etmiş ve birçok fıkrası dilden dile bölgeden bölgeye anlatılmıștır. Osmanlı Devleti topraklarının uzandığı hemen hemen her bölgede Nasreddin Hoca tanınmış, latifeleri anlatılmış ve

1 Gülmece kuramları hakkında ayrıntılı bilgi için bk. (Morreall, 1997; Bergson, 2014).

2 Konu hakkında ayrıntılı bilgi için bk. (Oğuz, 2000: 59-70). 
varyantlaşmıştır (Tarim, 2009: 370). Öte yandan Nasreddin Hoca'nın halk hafızasında oluşturulan bir kült kimlik olması da muhtemeldir. Halkın doğrudan dile getiremediği şikâyetlerine tercüman olan Nasreddin Hoca, anlatıldığı her bölgede nüktedan bir kahramana dönüşmüş ve yaşatıldığı coğrafyanın sosyo-kültürel özelliklerine göre Hoca Nasreddin, Nasreddin Ependi, Ependi, Molla Nasreddin şeklinde adlandırılmaya başlamış olmalıdır (İsmayil, 1994: 175-176).

Uygur Türklerinin edebiyatında eski dönemlerden itibaren latifelere benzeyen kısa anlatılar bulunmaktadır. Ancak bu anlatıların yaygınlaşıp olgunluğa erişmesi ve "efendi latifeleri" adıyla anılması tahmini XI. yüzyıldan sonraya tarihlenmektedir. Nitekim bu tarihten sonra tohumları atılmaya başlayan demokratik hareketler ve bu hareketler bağlamında zalim yöneticilere duyulan şikâyetler, Nasreddin Ependi kimliği etrafında toplanmış olmalıdır (İslam, 1982: 289; İsmayil, 1994: 172). Uygur Türkleri tarafından benimsenen ve yaşam biçimlerine göre şekillenen bu latifeler, güldürücü olmanın ötesinde Uygur toplumunun sosyo-kültürel hayatını yansıtması bakımından da ayrıca önem kazanmaktadır. Nitekim latifelerde Uygur toplumundaki adaletsizlik, yolsuzluk, zulüm ve cahillik gibi sosyal hadiseler şiddetle tenkit edilirken halkın hoşgörüsü ve zekâsı yüceltilmektedir. Bunların yanı sıra insan ilişkileri bağlamında önem taşıyan cimrilik, aptallık ve komiklik gibi münferit hususlar da ele alınmaktadır (İnayet, 1996: 149).

Nasreddin Efendi latifelerinin Doğu Türkistan coğrafyasına taşınmasında ortak dil, dini kimlik ve göç, ticaret, savaş gibi hususların etkili olduğunu söylemek mümkündür (Tarim, 2009: 371). Çeşitli vasıtalarla Anadolu coğrafyasından Doğu Türkistan'a taşınan bu "kimlik (ependi)", halk arasında fazlaca benimsenmiş olup günümüzde de yaşatılmaktadır. Nitekim aşağıdaki örnekler, Nasreddin Ependi'nin Uygur toplumundaki söz konusu yeri ve sözcülüğünü göstermesi bakımından kayda değerdir.

\section{Dünyanın Derdinden}

Bir gün Nasreddin Ependi'nin oğlu;

-Baba, Allah insanları neyden yaratmış? diye sormuş.

-Topraktan yaratmış- diye cevap vermiş Nasreddin Ependi.

-Kuru topraktan mı yoksa çamur yaparak mı? diye sormuş oğlu.

-Çamur yapıp, çamurdan yaratmış -demiş Ependi.

-Saman karıştırmış mı karıştırmamış mı?

- Ey akılsız yavrum, eğer sadece çamurdan yapıp içine saman karıştırmasaydı, baban dünyanın derdinden bugüne kadar parça parça olmaz mıydı? diye cevap vermiş Ependi (Gulam, 2006: 141; Yalçın ve Emet, 1995: 5). ${ }^{3}$

\section{Vermeyenin Bahanesi}

Komşusu Ependi'den kalbur istemiş,

Ependi:

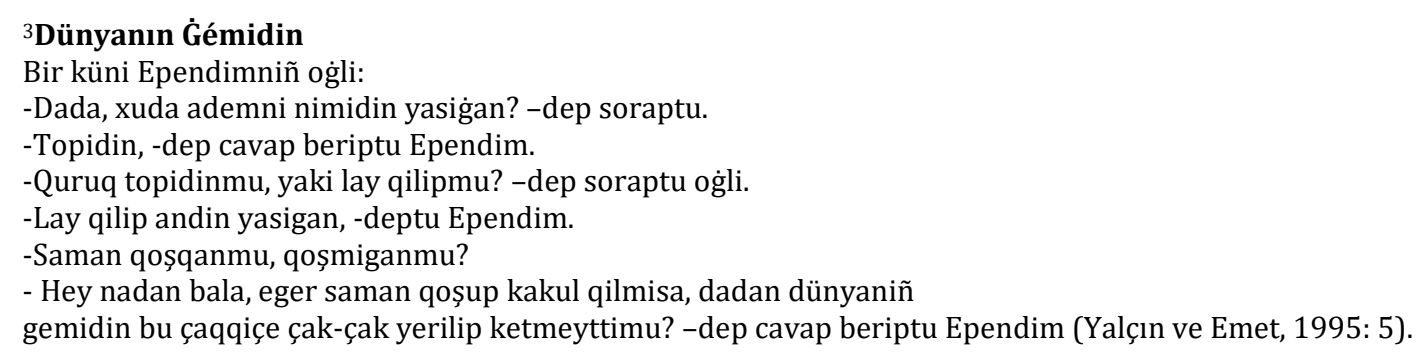


-Kardeşim vallahi verirdim ama kalbur boş değil, hanım içine su koymuş diye cevap vermiş. Komşusu şaşırıp;

- Ependim, kalbura da mi su konur?

-Hay akılsız, adamın canı vermek istemezse kalbura su koymak şöyle dursun, ipe un bile serer diye cevap vermiş Ependi (Yalçın ve Emet, 1995: 28). ${ }^{4}$

\section{İki Eşeğin Yükü}

Günlerden bir gün padişah ile vezir ava çıkarken Nasreddin Ependi'yi de beraberlerinde götürmüş. Yolda padişah ve vezir sıcaktan ceketlerini çıkarıp Nasrettin Ependi'ye vermişler. Padişah güçlükle yürüyen Ependi'ye bakarak:

- Ependim üzerinizdeki bir eşeğin yükü olmuş diye alay etmeye başlamış.

Ependi hemen;

- Hayır hazretleri, üzerimdeki bir eșeğin yükü değil, iki eşeğin yükü diye cevap vermiş (Yalçın ve Emet, 1995: 102; İslam, 1982: 288). ${ }^{5}$

\subsection{Seley Çakkan}

XIX. yüzyıl Uygur toplumunda Nasreddin Ependi dışında Seley Çakkan ve Molla Zeydin gibi estetik, ifade ve temsil gücü yüksek kişiler tarafından da halkın yönetimden beklentileri, arzu ve istekleri çeşitli latifeler vasıtasıyla dile getirilmiştir (Uygur Edebiyati Toğrisida: 291-293). Seley Çakkan ve Molla Zeydin aynı zamanda yetenekli birer halk şairi, saz ve söz ustasıdır. Ancak şiirleri fıkralarına oranla daha az bilinmektedir (Oğuz, 2015: 95).

Doğum tarihi ile ilgili farklı rivayetler bulunan Seley Çakkan, (1790/1816?) Kaşgar'ın Tokkuzak ilçesinin Opal köyünde ${ }^{6}$ dünyaya gelmiştir (Kaşgarl, 2008: 19; Utuk 2006: 185). Asıl adı Muhammet Salih olup halk arasında "Epçilem", "Gepçilem", "Bilgin", "Molla" ve "Çevik" gibi adlarla da tanınmaktadır. "Seley Çakkan" adı, pratik zekâsı ve hazırcevaplığı sebebiyle adına "Çakkan (çabuk, tez)" sıfatı eklenmesiyle oluşturulmuştur. Babası Muhammet Ahun olup kendisi, Uygur sözlü edebiyatının münevver temsilcilerinden ve rebap ustalarındandır (Kaşgarlı, 2008: 20-21). Seley Çakkan, babasının da desteğiyle küçük

\footnotetext{
${ }^{4}$ Bermesniñ Bahanisi

Bir kişi ependimdin gelvir sorap keptu.

- Burader, cenim bilen berettim, bikar emes, öydikiler gelvirge su qoyup qoyuptu, dep cavap beriptu. Hiliqi kiși heyran bolup:

-Ependim, gelvirgimu su qoyamdu dep soraptu.

- Hey exmeq, bermeslikke bana izligende gelvirge su qoyuş bu yaqta tursun, arqañgimu un besip qoyidu -dep cavapbériptu Ependim (Yalçın ve Emet, 1995: 28).

5İkki Éşekniñ Yükü

Bir küni padișa bilen vezir ovġa çiqqanda Ependimnimu bille élip çiqiptu. Yolda ular issiqlap kétip, çapanlirini yeşip, Ependimge artip qoyuptu. Padişa hasirap-hümüdep kelivatqan Ependimge qarap:

- Ependim, üstiñizdiki bir éşekniñ yüki boluptu, -dep zañlik qiliptu.

-Ependimmu derhal:

-Yoqsu texsir, üstümdiki ikki éşekniñ yüki! -dep cavap bériptu (Yalçın ve Emet, 1995: 102).

"Seley Çakkan "Adımı Sorarsan" türküsünde hayatı hakkında şu bilgilere yer vermektedir:

Etimni sorısañ Seley

Qeşqer béşi Opaldın.

Adımı sorarsan Seley

Kaşkar başı Opal'dan.

Ravap çélip oynaymen,

Korkmay loyı, ambaldın.

Rebap çalıp oynarım,

Léqemni sorısañ Çaqqan

Korkmam beyden, başkandan.

Lakabımı sorarsan Çakkan

Yürügümde otum bar.

Yüreğimde ateșim var.

Ezizane Qeşqerdek,

Qedim dergah yurtum bar.

Azizane Kaşgar gibi,

Eski dergah yurdum var (Kaşgarlı, 2008: 20).
} 
yaşlardan itibaren meşrep ${ }^{7}$, nahşa, oyun ve saz meclislerine katılıp kızıkçılık, hazır cevaplık ve sözmenlik öğrenmiş, gözlemleri vasıtasıyla kendisini yetiştirmiştir. Latifeleri 1830'lardan itibaren halk arasında yayılmaya başlamıştır (Utuk, 2006: 185). Seley Çakkan, (1850/1905?) memleketinde vefat etmiş ve Opal'da bulunan Hazreti Molla mezarlığına defnedilmiştir (Kaşgarl, 2008: 20).

Seley Çakkan latifeleri, güçlü eleştirel ve satirik bir yapıya sahip olmanın yanı sıra söz konusu nükteler vasıtasıyla Uygur toplumunu bir arada tutan kültürel değerlere veönemine dikkat çekmektedir (Muhemmetmusa, 2003: 69).

\section{Mezar Kazış}

Zordun Hâkim vazife vermek için Seley'e sormuş:

-Elinden padişaha ne tür bir hizmet etmek gelir?

-Mezar kazmak, demiş Seley Çakkan(Ebey ve İmin, 2006a: 272). ${ }^{8}$

$* * *$

\section{Kolaylık Olsun}

Seley Çakkan bir gün iki yarım kilo toz şeker almak için bakkala gitmiş. Bakkal toz şekeri iki yarım kilodan az vermiş. Bunu gören Seley Çakkan:

-Verdiğiniz şeker iki yarım kilodan az. Niye söylediğimi vermediniz? diye sormuş.

-Azıcık hafif olsa, kolay eve götürebilirsiniz. Ben size kolay olsun diye öyle yaptım diyecevap vermiş bakkal.

Seley Çakkan toz şekerin parasını verip kapıya geldiğinde bakkal seslenmiş:

-Arkadaşım, verdiğiniz para eksik.

-Ben de size parayı kolay sayasınız diye azıcık eksik verdim diye cevep vermiş Seley Çakkan (Kaşgarlı, 2008: 38-39; Ebey ve İmin, 2006a: 274). ${ }^{9}$

***

(Yakup Han) büyük bir toplantıda otururken:

- Benim zamanımda koyun sırtında turgay yuva yapar oldu, diye kendini övmüş.

- Doğru söylediniz, demiş Seley Çakkan,

\footnotetext{
7 Meşrep; "ziyafet", "keyif meclisi” ile "şölen" anlamına gelmekte olup (Necip, 2008: 269) "insanların bir araya gelerek yaptığı müzik ve danslı toplantı” olarak tanımlanmaktadır (UTIL, 1995: 128). Meşrepler hakkında ayrıntılı bilgi için bk. (GönelSönmez, 2017).

${ }^{8}$ Gör Kolaş

Zordun hakim iş tapşurmaq bolup Seleydin soraptu:

-Xanġa qandaq xizmet körsitiş qoluñdin kélidu?

-Gör kolaș,- deptu Seley Çaqqan (Ebey ve İmin, 2006a: 272).

${ }^{9}$ Asanliq Tuġdurup Bériş

Seley Çaqqan bir küni dukanġa kirip beş ciñ şéker aptu. Dukançi şékerni kem tatip qegezge orap bériptu. Buni körüp qalgan Seley Çaqqan:

-Bergen șékiriñiz beș ciñkelmeydu? Bu némeqilg̈iniñiz? -depsoraptu.

-Yeñgilrek bolsa asan ekétisiz, men sizge asanliq tuġdurup bedrim,- dep cavap bériptu dukançi.

Seley Çaqqan şékerniñ pulini pokey üstige qoyupla méngiptu. U téhi bosugigiga barmayla dukançi tovlaptu:

-Hey agine, bergen puliñiz kemġu?

-Menmu sizniñ sanişiñizġa asanliq tuġdurup bériş üçün pulni azraq bedrim,- deptu Seley Çaqqan (Kaşgarll, 2008: 38-39; Ebey ve İmin, 2006a: 274).
} 
- Hazretlerinizin zamanında turgay avlamak için sadece koyun sırtı kaldı ${ }^{10}$ (İslam, 1982: 291-292.

\subsection{Molla Zeydin}

Molla Zeydin, 1815 yılında Lükçün'ün Bağra köyünde çiftçi bir ailenin çocuğu olarak doğmuştur. Küçük yaşlardan itibaren medrese tahsili gördügü için halk arasında "molla" adıyla tanınmaktadır. Latifelerinin genel muhtevasını Lükçün yöneticileri ile emektar halk arasındaki ilişkiler oluşturmaktadır (Utuk, 2006: 186). Latife ve şiirlerindeki keskin hicivleri ve sivri dili nedeniyle Turfan Prensleri tarafından sekiz kez ordudan atılmıştır. Çinli Prens Eprudin tarafından kendisine yakınlık gösterilmiş, korumaya alınmıştır (Uçkuncan, 2009: 619). Ölüm tarihi hakkında farklı rivayetler bulunan Molla Zeydin, geçirmiş olduğu hastalık sebebiyle (1880/1900?) vefat etmiştir (Uçkuncan, 2009: 619; Utuk, 2006: 186). Molla Zeydin latifeleri kısa vakalarla birbirine bağlanıp mekân ve kronoloji gözetilerek Molla Zeydin Hekkide Kisse (Hevir, 1982) adıyla yayımlanmıştır ancak eser daha çok komik bir biyografik hatırat niteliğindedir (Özkan, 1992: 16).

Molla Zeydin'in yaşadığı dönem Mançu Qing hanedanının Turfan'da hâkimiyet sürdüğü yıllardır. Bu dönemde Uygur toplumunda yerli subaylar, zengin sömürücü sinıf ve yalancı sahtekâr din adamlarının otoriter gücü hâkim olup Uygurlar aynı zamanda çeşitli ırkçı siyasetlere maruz kalmışlardır. Bu karanlık dönemi yaşayan Molla Zeydin, sahtekâr din adamları, zalim yönetici ve sermayedarlara karşı kendi mizahı ile savașmıștır (Batu, 2018: 43).

\section{Zengin Adamın Göz Ağrısı}

Bir gün, zengin bir adamın gözü hastalanmış. Uzaktaki yakındaki hekimler gelip bakmış ama iyileştirememişler. Sonunda adam (kendisini tedavi etmesi için) Molla Zeydin'e yalvarmış. Molla Zeydin:

-Sizin gözünüzü tedavi edip edemeyeceğimi Hızır’a sormam lazım, demiş ve camiye doğru gitmiş, az sonra geri dönmüş ve zengin adama demiş ki:

Hızır, aslında sizin gözlerinize zarar vermek istemiyormuş ama birçok kişi insanlara farklı gözle baktığınız için sizi Hızır’a şikâyet etmiş. Hızır, mecburen sizin bir gözünüzü görmez etmiş. 0 yüzden bundan sonra insanlara farklı değil aynı gözde bakınız (Ebey ve İmin, 2006a: 233-234).11

\section{$* * *$}

\section{Ay ile Güneşin Saklanması}

Bir gün vali, aniden Molla Zeydin'a sormuş:

-Ay ile güneş niye bulutun arkasına saklanır?

-Molla Zeydin valiye:

\footnotetext{
${ }^{10}$ Be dölet çoñ bir sorunda olturup:

-Méniñ devrimde qoyniñ dümbiside turgay uvlaydigaan boldi- dep maxtiniptu.

-Rast éytitila, texsir, deptu Seley Çaqqan,

-Canabi aliliriniñ zamanida turg̉ay uvlaşqa peqet qoyniñ dümbisila qaldi (İslam, 1982: 291-292).

${ }^{11 B a y n i n ̃ ~ Q o ̈ z ~ A g ́ r i q i ~}$

Bir bay közi agrip qilip, yiraq- yéqindiki hékimlerni çaqirtip davalitiptu, lékin ünümi bolmaptu, axir Molla zeydinge yalvuruptu. Molla Zeydin:

-Silniñ közlirini sakaytişqa bolamdu, buni men xizirdin sorap baqay, - depla mescitke qarap méngiptu, bir hazadin kéyin qaytip kélip bayġa mundaq deptu, - xizir silige yetküzüp qoyuşni éyitti. Xizir eslide közlirige ziyan salmaqçi emes ikenduq, emma nurgun kişilerniñ erziçe, sili daim kişilerge ikki xil köz bilen qaraydikenla. Xizir amalsiz silniñ bir közlirini körmes qilip ağritip qoyuptu. Şuñga, buniñdin kéyin kişilerge bir xil köz bilen qarisila (Ebey ve İmin, 2006a: 233-234).
} 
-Gece vakti ay, karnı aç zavallıların acı çektiğini görünce adaletsizliğe dayanamayıp bulutun arkasına saklanır. Gündüz vakti, güneş çalışan halkın tarlada sıcaktan susadığını görünce onlara merhamet gösterip bulutun arkasına saklanır. Ay ile güneşin daima bulutun arkasına saklanmasının sırı budur, demiş (Ebey ve İmin, 2006a: 234).12

$* * *$

Turfan valisi maiyetindeki kişiler ve memleketin saygın kişilerini çağırıp ziyafet verir. Bu sırada Molla Zeydin'in burnunun üstüne bir pirinç tanesi kaldığını gören vali, misafirlerin önünde onu küçük düşürmek için:

-Hey, Molla Zeydin, mübarek olsun tepeye geyik çıkmış der ve kendi nüktesi hoşuna gidip kahkahayla gülünce burnu akar.

-Molla Zeydin, hemen cevap verip: “Onu görmek için mağaradan ayı çıktı” der (İslam, 1982: 292-293).13

Nasreddin Efendi, Seley Çakkan ve Molla Zeydin'in yanı sıra İsmayil Pahtacı, Molla Metiya (Sakaoğlu, 1995: 272) Şérin Dorğa, Rozi Karim, Usta Razi, Kasim Kizik ve İskender Hekkulu da (Ebey ve İmin, 2006a) Uygur Türkleri arasında bilinen diğer fikra tipleri olup halkın gözlem gücü ve temsil yeteneği ile buluşarak çeşitli latifelerde yaşatılıp çeşitli zaman ve mekânlara aktarılmaktadır.

\section{2. Çakçak}

Kelime olarak "şaka" anlamına gelen (Necip, 2008: 68) çakçak kavramı, Uygur Tiliniñ İzahlik Luğatinde "insanları güldürmek, eğlendirmek amacıyla söylenen söz, hareket" olarak açıklanmaktadır (1991: 645). Çakçaklar, insanları güldüren nükteli kısa sözlerden müteşekkil olup köklü bir geçmişe ve Uygur Türklerinin toplumsal hayatında önemli bir yere sahiptir. Çakçaklar, geleneksel bir forma sahiptir ve diyalog şeklinde icra edilirler. Nitekim çakçakların icrası en az iki kişi tarafından gerçekleştirilmekte ve çakçak icra eden kişiye çakçakçı; çakçak icrasına çakçaklaşmak adı verilmektedir. Hazırcevaplık, nüktedanlık ve pratik zekâ gerektiren çakçak icrasında rekabet duygusu ve mizah ön plandadır. İcra sırasında mizahın dozu artarak devam etmeli, her cevap bir öncekinden daha fazla komik unsura sahip olmalıdır. Dikkat edilmesi gerek diğer bir husus, çakçakçıların belirlenen muhtevaya bağlı kalmasıdır (Tarim, 2009: 393). Çakçak söyleme geleneğinde, icracı kişiler ve icra ortamı gibi değişkenlere bağlı olarak da birtakım kısıtlamalar mevcuttur. Örneğin; küçükler büyüklere, erkekler kadınlara çakçak söylemekten imtina ederler (Rahman, 1996: 200).

Çakçakçılar, söz ustalığı, gözlem gücü, mübalağa ve tasvir yeteneğine sahip, alegorik imajlara hâkim olmalıdır (Tarim, 2009: 394; Rahman, 1996: 198). Nitekim çakçakların sıradan söz oyunları olmaması ve icrasının çeşitli yetenekler gerektirmesi sebebiyle Uygur

\footnotetext{
${ }^{12}$ Ay bilen Künniñ Möküvéliși

Bir küni vañ uştumtut Molla Zeydindin soraptu:

-Ay bilen kün néme üçün bulutniñ arqisiġa mökünivalidu?

-Molla Zeydin Vañga:

-Axşimi ay qorsiqi aç capakeşlerniñ peryad çekkenlikini añlap, ularg̉a iç ag̉itip teñsizlikke çidimay bulutniñ keynige ötüvalidu. Kündüzi bolsa, quyaş namratlarniñ étiz- ériqlarda işlep, ussap géli qurup kétivatkanliqini körüp, ularga rehmi kélip umu bulutniñ arkisiġa ötüvalidu. Ay bilen künniñ daim bulutniñ keynige mükünüvélişiniñ siri şu yerde,- deptu (Ebey ve İmin, 2006a: 234).

${ }^{13}$ Turpan vañi qol astidiki emeldarlar ve yurt muteverlirini çaqirip, dastixan yigișturulgandin kéyin, Molla Zeydinniñ burni üstide bir tal gürüçniñ çaplişip qalganliqini körgen vañ méhmanlar aldida uni gepte çüşürüş üçün:

-He, Molla Zeydin, mubarek bolsun, doñniñ üstige kiyik çiqivaptu- deptu ve öz çaqçig̈idin hozurlinip qattiq külgeçke burnidin potlisi çuvulup çiqiptu.

Molla Zeydin derhal cavap qayturup-uni korüş üçün kamadin éyiq çiqiptu (İslam, 1982: 292-293).
} 
Türkleri arasında çakçakçılar, nahşacılar ve sazendeler kadar iktidara sahiptir (Tarim, 2009: 394).

Uygurlar meșrep, seyle-baravet, toy ve düğün gibi toplu eğlence merasimlerinde, dinlenme ve eğlenme zamanlarında sıklıkla çakçak icra ederler (Rahman, 1996: 198). Çakçaklar, icra usullerine göre çeșitli adlarla anılmaktadır:

Rubiru Çakçak: İki çakçakçının yüz yüze diyalogu şeklinde icra edilir. Söz gelimi çakçakçılardan biri diğerinin kıyafeti veya hareketi üzerinde bir hicviye yapar, o da aynı muhtevada bir nükte ile cevap verir. Böylece "atışma" başlamış olur. Diyaloglarda sıklıkla mübalağa ve tasvire başvurulur (Tarim, 2009: 396).

Çaçma Çakçak: Aynı zamanda bağlanma çakçak olarak da adlandırılan bu türde ikiden fazla çakçakçının katılımı esas olup icra, sıra gözetmeksizin sürdürülür. Belirlenen genel bir muhteva etrafında icra edilen bu çakçaklarda tek bir tema sınırlaması yoktur. Örneğin; bir çakçakçı sofradaki yemek ile söze başladığında diğeri pişirilen balık ile ilgili söz söyleyebilir. Sudan yağmura, yağmurdan buluta, buluttan gökyüzüne, gökyüzünden güneşe ve aya... şeklinde sürdürülebilen çağrışımlı bir icra mümkündür (Tarim, 2009: 397).

Aylanma Çakçak: Bu tür, usta ve meşhur bir çakçakçının icrasıyla gerçekleștirilir. Çakçakların muhtevası genellikle mevcut topluluktaki kişiler ile ilgilidir (Tarim, 2009: 397).

Tercüme Çakçak: Özellikle İli bölgesinde son zamanlarda görülen bir çakçak türü olup çakçakçı, yabancı dillerden birinin telaffuzu bağlamında ürettiği komik unsurlar vasıtasıyla sanatını icra eder (Tarim, 2009: 397-398).

Taklidî Çakçak: Cimri, sarhoş, tembel, açgözlü ve yalancı gibi toplumsal hayatta eleştiriye maruz kalan tiplerin taklit edilmesi esasına dayanan bir çakçak türüdür (Tarim, 2009: 398).

Lekemlik (Lakaplı) Çakçak: Bu tür çakçaklar, mevcut topluluktaki kişilere çeşitli komik unsurlar vasitasıyla lakap verilmesi veya kişinin var olan lakabı üzerinden çakçak söylenmesi şeklinde icra edilir (İsmayil, 1994: 189-190; Tarim, 2009: 398; Rahman, 1996: 199).

Latifeli Çakçak: Bu tür çakçakların içinde latife (fıkra) yer alır. Çakçakçı güldürmenin yanı sıra fıkradaki nükteye dikkat çekmeye çalışır (Tarim, 2009: 399).

Kafiyeli Çakçak: Bu tür çakçaklar, iki çakçakçı arasında manzum şekilde icra edilir. İcra, ilk çakçakçının söylediği kafiye ile devam etmek zorundadır (İsmayil, 1994: 191; Tarim, 2009: 399; Rahman, 1996: 199).

Çakçaklar sözlü gelenekten beslenmesi, mizahi yapısı, güldürme ve eleştirme işlevi bakımından latifeler ile benzerlik göstermekte ve sıklıkla karıştırılmaktadır. Nitekim her iki tür, mizahın yanı sıra felsefi ve estetik özellikler göstermekle birlikte kurulmaları bağlamında diyalog temelinde şekillenmektedir (Géni, 2009: 10-11). Latifelerde tahkiye unsuru daha ön planda olup zaman ve mekân sınırlı değildir. Çakçaklarda ise dile getirilen mekân, bilinen bir mekândır (Tarim, 2009: 394). Öyle ki betimlenen şahıs ve mekânın gerçekçiliği, inandırıcılığı artırması sebebiyle çakçakların mizahi gücünü de arttırmaktadır. Latifelerin niteliğini, nüktesinin kuvveti belirlerken çakçakların niteliğini, kurulmasındaki komik unsurların kuvveti belirlemektedir. Latifelerde güldürücü unsur, anlatının sonunda yer almaktadır. Çakçaklar ise kurulması itibariyle mümkün olduğunca çok komik unsurdan oluşur ve dinleyicilerin icra sırasındaki gülme sıklığı çakçakların gücünü artırır. Yine latife icrası için kalabalık bir tören, toplantı ya da merasim gerekmezken çakçak icraları genellikle kalabalık meclislerde yapılır (Géni, 2009: 11-12).

Çakçaklar sözlü geleneğin ürünü olması sebebiyle birçoğu yazıya geçirilmeden unutulmuş ve günümüze ulaşamamıştır ancak son zamanlarda önemli bir çakçak ustası olan Hésam 
Kurban'ın çakçakları hakkında yapılan birtakım çalışmalar ve derleme faaliyetleri bulunmaktadır.

\subsection{Hésam Kurban}

Hisam Kurban, 1930 yılında Gulca şehrinde esnaf bir ailenin çocuğu olarak dünyaya gelmiştir. ${ }^{14}$ 1940-1944 yılları arasında tahsil görmüş olup 1951-1961 yıllarında Gulca sanat ekibine katılmıştır. 1961-1966 yıllarında çiftçilik yapan Hisam Kurban, 1966-1980 döneminde sanatsal faaliyetlerine devam etmiştir. 1980 yılında düzenlenen bir kongrede yeteneğini sergileme fırsatı bulmuş ve bu vesile ile Gulca Kültür Yurdunda işe başlamıştır. Hisam Kurban'ın babası, döneminde tanınmış bir çakçakçı olup Hisam, babasının tesiri ile 11-12 yaşlarında çakçakçılık yapmaya başlamıştır. Kısa zaman sonra "Yaşayan Nasreddin Ependi" adıyla Uygur toplumunda tanınmıştır (Ebey ve İmin, 2006b: 1-2; Kadir, 2011: 3140; İnayet, 2013: 166).

Hisam Kurban hakkındaki ilk çalışmalar Mahmut Muhemmet'e ait olup yapılan derleme "Hisam Çakçakliri" adıyla yayımlanmıștır (Davut, 2000: 46; Tarim, 2009: 395; İnayet, 2013: 166-167).

Hisam Kurban çakçaklarının muhtevasına ve şahıslar kadrosuna genel olarak bakıldığında Nasreddin Ependi, Seley Çakkan ve Molla Zeydin fıkralarında olduğu gibi sınıf çatışması ve zalim yöneticiler yer almamaktadır. Çakçakların başkahramanı Hisam Kurban olmakla birlikte, Hisam Kurban'ın biyografisindeki gerçek hayat ve insan yaşamındaki türlü hadiseler mizah vasıtasıyla anlatılmaktadır (Batu, 2018: 53).

\section{Adaletin Ölçüsü}

Hisam'ın çalıştığı dairenin başkanı her zaman kendi bildiğine doğru diyen bir kişidir. Hisam, başkanın bu huyunu eleştirdiği için defalarca firça yer. Günlerden bir gün çalıştığı yerde, “Hakikatin ölçüsü nedir?” konulu bir tartışma olur. Hisam, ses çıkarmadan bir kenarda oturur. Bir süre sonra başkan Hisam'a sorar:

-Hisam, siz de kendi görüşünüzü söyleyin bakalım, "Hakikatin ölçüsü nedir?"

Hisam:

-Her şey ortada, başkanım, hakikatin ölçüsü sizsiniz, diye cevap verir (Ebey ve İmin, 2006b: 6). ${ }^{15}$

\section{Tekerlek Yaptırmak}

İyi planlanmadığı için beş senede üç defa evini yıkmaya mecbur kalan Hisam, yüklü bir miktar para almak için ilçe hükümetine dilekçe verir.

İlçe başkanı Hisam'a, "bu kadar parayı ne yapacaksın?" diye sorar.

Üç oda bir salonluk bir ev sığacak bir tekerlek yaptırmak istiyorum, der Hisam.

\footnotetext{
${ }^{14}$ Hisam Kurban hakkında ayrıntılı bilgi için bk. (Emet, 2013).

${ }^{15}$ Heqiqetniñ Ölçimi

Hésam işleydiġan idariniñ başliqi öz gépinila rast qildig̉an kişi iken. Hésam başliñiniñ bu micezige bir neççe qitim pikir bérip dekkimu yégeniken.

Bir küni idaride -Heqiqetniñ ölçimi néme? Dégen melse üstide munazire qozgiliptu. Hésam ünçiqamay olturuptu. Bir hazadin kéyin başliq:

-Hésam, sizmu öz tonuşiñizni dep béqiñ,- deptiken, Hésam:

-Bu intayin oçuq gepqu, heqiqetniñ ölçimi sizniñ söziñiz, -dep cavap bériptu (Ebey ve İmin, 2006b: 6).
} 
-Bu kadar büyük tekerleği ne yapacaksın?- diye sorar ilçe başkanı Hisam’a.

-Yaptırdığım evlerin hepsini plana uygun değil, diye devlet yıktı. Sürekli yeni ev yaptırmaktan bıktım. Onun için bu defa yapacağım evi tekerlek üzerine yapayım diyorum. Eğer yine plana uygun değil derlerse sürer, başka tarafa götürürüm, der Hisam(Ebey ve İmin, 2006b:16).16

\section{Günah Olur}

Bir gün Hisam, hatim okunan bir yerde cemaatle birlikte oturur. Köşe başında oturan imam ikide bir:

-İnsan resmi olan evde Kuran-ı Kerim okumak günah, duvara resim asmak günah, diyerek evin duvarındaki bütün resimleri bir bir indirtir. Hisam, bir ara imamın önüne konmuș zarfın içindeki parayı alıp ev sahibine verir ve "Bunu da alın."der. Bunu gören imam çok kızar:

-Hisam, ne yapıyorsun? diye bağırır. Hisam imama sakin bir şekilde:

-Sayın Hoca Efendi, baktım paranın üzerinde de insan resmi var, siz de günaha ortak olmayın diye öyle yaptım, der (Ebey ve İmin, 2006b: 52). ${ }^{17}$

Doğu Türkistan coğrafyasına bakıldığında çakçakların özellikle İli bölgesinde yaygınlıkla icra edildiği tespit edilmektedir. Hisam Kurban dışında bölgenin önemli çakçakçıları arasında Rozi Abduveli, İbrahim Ablahan, Ebeyhan Çokur, Bolus Nizamidin, Sattar Baki, Dilmurat Sabir (1957-1986), Sali Savut, Leti Imin, Reşid Muhemmed, Kamil Hocaehmet, Mecid Abdurahman, Şevket Cumaş, Hibi (Hebibullah) Abdurrehim, Turdiahun Rozem (1969-2012), Mahibeder İbrahim, Halmurat Ömer, Yakup Haci, Ababekri Obul, Sabircan Sadık ve Perhat Mahmut'un bulunduğunu söylemek mümkündür (URL-1).

\section{Yumur}

Uygur Tiliniñ İzahlik Luğatinde "yaşamdaki komik, ilginç vakaları, insanların eksikliklerini, kusurlarını eleștirel bir dil, mizahi bir üslup ve sanatsal bir formda tasvir eden edebi eserler" (1998: 633) olarak tanımlanan yumur kavramı, İnayet'e göre Türkiye sahasında fikra türünü karşılamaktadır. Ancak Uygurlar arasında bu tür için en çok tercih edilen kavram "latipe"dir (İnayet, 2013: 65). Latince "humor" kelimesinden gelen yumur kavramının Uygur Türkçesindeki sözlük karşılığı "kamçilaş" (iğneleme, kinaye) olup eleştirel yönü ön planda olan mizahi anlatmalar için kullanılmaktadır. Sözlü gelenekte yaratılıp aktarılan yumurların

\footnotetext{
16 Ġaltek Buyruş

Pilan muqim bolmigaç̧qa beş yilda üç qitim öy çéqișqa mecbur bolġan Hésam nurġun pulga iltimas yézip dadüy şucisiga élipbériptu.

-Bunçe pulni néme qilmaqçisiz? -dep soraptu şuci.

-Üç iğiz öy patidig̉an galtek yasatmaqçimen, -deptu Hésam ciddiy halda.

-Munçe çoñ galtekni néme qilisiz? -deptu şuci.

-Salgan öyum hedésila pilanġa tog̉ra kelmey, tola öy çiqip hardim, -deptu Hésam,- emdi öyni aşu galtekkila salay deymen. Pilanlaşqa taqişip qalgudek bolsa derhal sörep ekétimen (Ebey ve İmin, 2006b: 16).

17 Gunah Bolidu

Bir küni Hésam camaet bilen xetmiquran céyida bile bolup qaptu. Törde olturgan mehelle imami hedep:

-Ademniñ süriti bar öyde tekbir éyitiş gunah bolidu, tamġa resim çaplaş gunah bolidu...,-devérip, öydeki hemmila resim evladini alduruvétiptu. Hésam bir çagda imamniñ aldig̉a qoyulgan konvért içidiki beş somluq pulni aptude, sahipxanga bérip:

-Bunimu ekétinglar,- deptu. İmamniñ közi çekçiyiptu- de:

-Hésamidin, bu néme iş? - deptu pokandek qizirip. Hésam çüşendürüptu:

-Teqsir, qarisam puldimu adem süriti bar iken, silini gunahqa șérik bolup qalmisun-dédim (Ebey ve İmin, 2006b: $52)$.
} 
en önemli özelliği, muhtevasının kinaye vasıtasıyla kurgulanması ve gündelik yaşamdaki gözlemlerden beslenmesidir. Öyle ki gündelik hayatta insanların dikkatini çekmeyecek küçük detaylar dahi yumurların konusunu oluşturabilmektedir. Toplumsal meseleler, sınıf çatışması ve ideolojik kaygılar gibi her türlü toplumsal hassasiyet, kara mizahi yapısıyla yumurlarda işlenebilmektedir. Bu yönüyle yumurların toplumun aynası mahiyetinde olduğunu söylemek mümkündür (Ömer, 2013: 462-466).

Yapı bakımından kısa hacimli olan yumurlar, gelenekte "isimli" ve "isimsiz" olmak üzere icra edilmektedir. İsimli yumurlarda, muhtevayı en iyi şekilde özetleyecek birkaç kelime yumurların başlığında yer almaktadır. İsimsiz yumurlar, kurulması bakımından daha basittir ve genellikle diyaloglardan oluşurlar (Ömer, 2013: 476-478).

Yumurlarda da tıpkı latifeler gibi nükte, anlatının sonunda yer alır ancak latifeler gibi güldürürken düşündürme işlevi ön planda değildir. Yumurların güldürücü yönü, çakçaklar kadar güçlü olmayıp kinaye ile kara mizahın birleştiği noktada yer almaktadır (Ömer, 2013: 483-484).

Yumurlar, Uygur Türkleri arasında sözlü gelenekte yaratılıp aktarılmakla birlikte Tarim, Keşker, Maybulak, Turpan, Kumul Edebiyati, Şincañ Geziti, Ürümçi Keçlik Geziti, Şincañ Ösmürliri ve Tarim Ğunçiliri gibi dergi ve gazetelerde de yayımlanmaktadır (Ömer, 2013: 493).

\section{Kara Karpuz}

İskender Hekkulu, bisikletinin arkasına bir karpuzu dengeli bir şekilde koyar, onu görüp merak edenlerden biri sorar:

-Karpuzu yemeyecek miyiz? der.

İskender ona bakarak:

-Sizler kızıl karpuz yiyin, bu kara karpuz! der18 (Ömer, 2013: 466-467).

Birkaç kişi nasıl dinlendikleri hakkında sohbet ederken birisi:

-Ben sabah 10'a kadar huzur içinde dinlendim, der. Bunu anlayan biri:

-O halde saat 10'a kadar uyudun desene, der.

-Yok, ben uyumadım bizim hanım uyudu, diye cevap verir adam ${ }^{19}$ (Ömer 2013: 476-477).

***

\section{Şeftali Yetişinceye Kadar Beklemek}

İdam cezası hüküm kılınan bir katilin idam günü gelmişti.

Gardiyan: Sabah kahvaltıda ne yemek istersin?

Katil: Şeftali isterim.

\footnotetext{
${ }^{18}$ Qara Tavuz

İskender Heqqulu vélisipitniñ arqisig̉a bir tavuzni téñip kétip barsa, uni tartip çiqirip soraq qilganlardin biri:

- Tavuzunñi yémeymiz mu? deptu.

İskender uniñga qarapmu qoymastin:

- Siler qizil tavuz yeñlar, bu qara tavuz! deptu (Ömer, 2013: 466-467).

${ }^{19}$ Bir neççe adem dem élişni qandaq ötqüzüvatqanliqi toġrisida parañ sélişivatqaniken, aridin bireylen:

-Men etigen saat 10 giç̧e behuzur aram alimen, deptu. Buni añligan bireylen:

-Undaqta saat 10 giçe uxlaydikensen, de-deptu.

-Yaq, men uxlimaymen, ayalim uxlaydu-dep cavab bériptu adem (Ömer, 2013: 476-477).
} 
Gardiyan: Biliyorsun ki kış mevsimindeyiz, şeftaliyi nereden bulalım?

Katil: Hiç acelesi yok. Ben şeftali yetişinceye kadar beklerim²0 (Ömer 2013: 480-481).

Bir çocuk arkadaşına:

-Ben büyüyünce bekçi olup babamın izinden gideceğim, der.

-Baban bekçi mi? der arkadaşı.

-Yok, bekçi değil, hırsız, der çocuk²1 (Ömer, 2013: 498).

\section{Laf (Lap)}

Uygur Tilinin İzahlik Lugatinde; “uygun olmayan, mübalağalı, yalan söz” (1994: 893) olarak tanımlanan laflar, Uygur sözlü edebiyatının eleştirel nitelikteki türlerinden biri olup toplumsal yaşamdaki çeşitli gözlemleri, çeşitli söz sanatları vasıtasıyla işleyen küçük hacimli, sözlü hikâyelerdir. Laf (lap) icra eden kişiye lafçı (lapçi) adı verilmektedir (Tarim, 2009: 404).

Lafçılar, yaşamış oldukları veya gözlemledikleri olayları güldürmek ve eğlendirmek maksadıyla anlatırlar. Anlatım sırasında sıklıkla mübalağa ve tasvire başvururlar. Çakçaklar gibi genellikle iki kişinin diyalogu vasıtasıyla icra edilen lafların atışmaya benzeyen yapısı dolayısıyla rekabet ön plandadır. Lafçılar, sosyal gözlem gücü ve hikâye etme yeteneğine sahip olmakla birlikte aynı zamanda hazır cevap ve pratik zekâlı da olmalıdır (Tarim, 2009: 404-407).

Uygur halk lafları, müstakil bir tür olmakla birlikte çöçek, latife ve çakçakların içinde de icra edilmektedir. Örneğin; meşhur çakçakçı Hésam Kurban, çakçak icrası sırasında laflardan ustalıkla faydalanmaktadır (Tarim, 2009: 408).

Kavun

Bir lafçı bir lafçıya (dedi):

-Benim yetiştirdiğim kavunlar öyle büyüdü ki, birini sekiz kişi gönlünce yese yine bitiremez.

O zaman ikincisi (dedi):

-Kavunun büyüklüğü değil tatlılığı önemli. Benim yetiştirdiğim kavunlardan birini çocuklarım yedi, tatlılığından birbirlerine yapıştılar, sonra da o şekilde uyuyakaldılar. Ertesi gün kovayla su saçıp ikisini birbirinden ayırabildim, kalan dördünü yapışmış şekilde okula gönderdim (Ebey ve İmin, 2006c: 9). ${ }^{22}$

\footnotetext{
${ }^{20}$ Şaptul Pişqiçe Saqlay

Ölüm cazasiga hökümqilingan bir bir cinayetçiniñ ölüm cazasi icra qiliş küni yétip kelgen idi. Saqçi: Etigenlik tamiqiñga néme yéyişini xalaysen?

Cinayetçi: Şaptul yégüm bar.

Saqçi: Özüñ bilisen, hezir qiș pesli tursa, şaptulni nedin tapimiz?

Cinayetçi: Héç veqesi yoq. Men şaptul pişqiçe saqlay (Ömer, 2013: 480-481).

21 Bir bala aginisige:

-Men çoñ bolsam saqçi bolup, dadamniñ izini basimen, deptu.

-Dadañ saqçi mu? Deptu ag̉inisi.

-Yaq, saqçi emes, og̉ri, deptu bala (Ömer, 2013: 498).

${ }^{22}$ Qog்un

Bir lapçi yene bir lapçig̉a deptu:

-Men tériġan qog̉unlar şundaq oxşidiki, birni piçip sekkiz adem puxadin çiqqudek yések, yene éşip qaldi.

Şu çag̉da ikkinçisi deptu:
} 


\section{Kanalda Yağ Aktı}

Bir lafçı bir lafçıya (dedi):

-Geçen gün misafir çağırdım. Mezelerimin çokluğundan sofranın iki tarafında oturan misafirler birbirini göremedi.

-Şu kadar işle mi övünüyorsun sen? dedi Osman Böre. Ben bir kez misafir çağırmıştım, hanım öyle yağlı bir pilav yaptı ki, pilavı yiyen misafirler karşıdaki kanalda ellerini yıkamıştı, kanaldan günlerce yağ aktı (Ebey ve İmin, 2006c: 83).23

$* * *$

\section{Kabak ile Kazan}

Bir lafçı bir lafçıya (dedi):

-Geçen yaz kabak ektik, öyle bir büyüdü ki nasıl anlatayım? Bir gün komşumuzun buzağısı kayboldu, bir hafta boyunca aramadığı yer kalmadı lakin bulamadı. Sonra baktı ki bizim kabağın içine girmiş.

Başka birisi bu sözü (mübalağayı) anlayıp:

-Benim büyük babamın bir kazanı vardı. Ona ak kanalın suyunu bağlasan taşmazdı, der.

-Palavra atmasana birader, o kadar büyük kazan mı olur? der üçüncü bir (kişi). 0 zaman dördüncü (kişi):

-Böyle kazan olmasa buzağıyı gizleyebilen kabağı nasıl pişireceksin? der (Ebey ve İmin, 2006c: 84) ${ }^{24}$.

\section{Kizık}

"Kızık" kelimesi Uygur Türkçesinde "harareti, derecesi yüksek" (UTİL, 1994: 406) anlamına gelmekte olup Yeni Uygur Türkçesi sözlüğünde bu icrayı üstlenen "kızıkçılar", "soytarı" (Necip, 2008: 240) şeklinde açıklanmaktadır. Nitekim kızıkçılar, çeşitli söz oyunları ve komik ögeler vasıtasıyla eğlenceyi artıran komedyenlerdir.

Halk kızıkları, latifelere benzemekle birlikte kısa hacimli komik hareketler eşliğinde icra edilen hikâyelerdir. Kızıkçılık anlatıları, mizahi ve eleştirel bir üsluba sahip olup tarihi şahıslar etrafında teşekkül eden olayları referans alırlar. Kızıkçılar tarafından icra edilen hikâyelerde, günlük yaşamdaki aksaklıklar, mübalağa ve mizah ile yoğrularak ișlenir.

-Qog̉un dégen yoġan bolsila hésab mu, muhimi tatliqliqi. Men tériġan qog̉unlardin birni balilirim piçip yévidi, tatliqidin balilar bir birige çaplişip qélip, şu çaplaşqan pétiçe uxlişip qaptu. Etisi etigende çélek bilen su çéçip ikkisini aran acrattim, qalġan tötini çaplaqliq péti mektepke yolġa saldim (Ebey ve İmin, 2006c: 9).

230̈steñde May Aqti

-Ötkende méhman çaqirip, tizivetken mezelirimniñ köplükidin dastixanniñ ikki teripidi olturgan méhmanlar bir birini körelmey qaldi.

-Şunçilik iştinmu maxtinamsen? deptu Osman Böre. Men bir qétim méhman çaqirganidim, xotun şundaq mayliq polu ettiki, poluni yégen méhmanlar işik aldidiki östeñde qolini yuyuvidi, östeñde neççe küngiçe may aqti (Ebey ve İmin, 2006c: 83).

${ }^{24}$ Kava bilen Qazan

-Ötken yili yazda kava térividuq, şunda aynip oxşap kettiki, nemesini dey. Bir küni qoşnimizniñ moziyi yoqlip ketti, bir heptigiçe izdimigen yéri qalmadi, lékin mozayni tapalmidi. Kéyin qarisa, bizniñ bir kaviniñ içige kirivalganiken.

Uniñga oxşaşla biri bu gepni añlap:

-Meniñ çoñ dadamniñ bir qazini bar idi, uniñga aqösteñniñ süyini başlisimu toşmaydu, deptu.

-Po atmisañçu, burader, şundaqmu yoġan qazan bolamdu? deptu üçinçi biri. Şu çag̉da tötinçisi:

-Şundaq qazan bolmisa, mozay mökünüvalidigan kavini némide pişuridu? deptu (Ebey ve İmin, 2006c: 84). 
Nitekim halkın duygularına tercüman olan bu temsiller, halk tarafından ilgiyle izlenmekte ve benimsenmektedir. Kızıkçllık icralarında kahramanların söz ve hareketleri beklenmedik şekilde gerçekleşmektedir. Kızıkçılar, ele aldıkları kahramanları derinlemesine işlemekte ve icra sırasında sözlerini esirgememektedirler. Kızıkçıların hikâyelerindeki kahramanlar, genellikle belirli şahıslar etrafında toplanmaktadır. $\mathrm{Bu}$ merkezileșme, hikâye kahramanlarının ününün artmasına hatta farklı ülkelerde tanınmasına vesile olmaktadır (Turdi, 1985: 295-297).

Kızıkçılar, Uygur Türkleri arasında yapılan eğlence meclislerinin, törenlerin, merasim ve kutlamaların nahşa, ussul25, müzik ve latife gibi her alanında hüner sergilemektedir (Abliz, 2009: 10-11). Nitekim meșreplerde müzisyenlerin dinlenmesini sağlamak, meşrep törenini canlandırmak ve eğlenmek amacıyla kostümlü ve kostümsüz çeşitli kızıkçılık ussulleri ve oyunları da icra edilmektedir (Davut ve Abliz, 2015:167). Bu icra sırasında kızıkçılar, kaz, at, kaplan, eșek, deve; asker, tercüman, doktor, bakkal, kasap gibi icra edilecek oyunun temasına uygun olacak şekilde çeşitli roller üstlenmektedirler (Abliz, 2009: 10-11). Öyle ki her bölgede belirli kızıkçılık oyunları ile adı anılan usta kızıkçılar bulunmaktadır. Örneğin Niviyhan "şir (aslan) ussulünün", Yenisar'ınYeniyer köyünden Abdurusul Abdureşit "eşek oyununun", "Mekit'in Gazköl köyünden Eysa Tohti "esker kobul kılış (asker kabul etme) oyununun", Mamut Sunay "sunay (zurna) oyununun", Yantak köyünden Ömer Hüseyin ile Aktu'dan Abdukadir Memet "bahşi oyununun" ve Mekit'ten Yüsüvahun "yalguz kişilik çelişiş (tek kişilik güreş)" oyununun usta kızıkçıları arasındadır (Davut ve Abliz, 2015:167-168). Bu kızıkçılık oyun ve ussullerinin birkaçının icrası şu şekildedir:

Şir (Aslan) Ussulü: Kadın erkek farkı gözetmeksizin oynanan bu oyunda herkesin elinde kırmızı ve yeşil bir mendil, ağzında bir gül bulunur. Müziğin ritmine uygun olarak aslanın hareketleri taklit edilip (Davut ve Muhpul, 2011a: 60) bir çift aslanın birbiriyle oynaması, kur yapması ve erkek aslanın dişiye heybetini göstermesi gibi hareketleri sembolize edilir. Bu ussulde bazen farklı vahşi hayvanlar da sembolize edilebilir. Ussulü, aslan kılığına girmiş iki erkek oynar ve özellikle baş kısımlarının aslana benzetilmesine gayret gösterilir (Davut ve Muhpul, 2011b: 79).

Sunay (Zurna) Oyunu: Bir kızıkçının burnunu tutup ağzı ile zurna sesini taklit etmesi vasitasiyla oynanır (Davut ve Abliz, 2015: 277).

Bahşi, Dahan (Efsuncu) Oyunu: Yenisar, Aktu ve Dolan bölgelerinde oynanan kızıkçllık oyunlarından biridir. Bir bahşi, bir hasta ve üç tefçi olmak üzere toplam beş kişi ile oynanır. Oyunda rol alan kişilerin hepsi erkek olup hasta rolünü oynayacak erkek, kadın kılığına girer. Hazırlık tamamlanınca bir yün ipin ucuna tuğ takılır. Hasta olan kişi bu tuğu tutarken aynı zamanda peri oyunundaki ${ }^{26}$ hareketleri taklit eder. Bahşi dua okumaya ve cin çağırmaya başlar. Elindeki hançeri hastaya sürer. Hasta tuhaf hareketler yapmaya başlar.

\footnotetext{
25 Hareket sanatı veya hareket dili olarak bilinen ussul (halk dansı), Uygur Türklerinin bayram ve eğlence kültürünün vazgeçilmez unsurları arasındadır (Hebibulla, 2000: 432-435).

${ }^{26}$ Peri Oyunu, Uygur şamanların tedavi yöntemlerinden biri olup şu şekilde uygulanmaktadır: Büyük karanlık bir odanın içine tuğ bağlanır. Yani yün ip (arğamça)in bir ucu yerdeki kazığa, diğer ucu ise bacaya bağlanır. İpin bacaya bağlanan ucuna "yurun" veya "jurun” diye adlandırılan çeșitli renkteki kumaș parçaları (kurak), elma ve söğüt dalları bağlanır. Hasta olan kişi, bu tuğu sıkıca tutup oturur. Üç veya beş bahşı, perihonluk elbiselerini giyip (çeşitli renklerden oluşan kumaş parçalarını birleştirerek dikilen elbise) tuğ çevresinde yarı çember şeklini oluştururlar. Üç bahşı tef çalar. Bahşılardan biri perihon başı olarak elindeki kötü ruhu kovalayan sopa veya bir avuç sögüt ağacı parçasıyla efsun (özel bestelenmiş bir şiir) okumaya başlar. Bahşılar, hastayı tuğ çevresinde tef eşliğinde dönmeye davet eder. Baş perihon da dönmeye başlar. Hastanın dönecek gücü kalmayıp oturursa, baş perihon elindeki "efsun sopası"yla hastaya vurarak onu dönmeye zorlar. Bahşıların şarkıları gittikçe yükselir. Bazen hasta bayılıp düşer. Bayılmak perihonlara göre iyiliğe işarettir. $\mathrm{Bu}$, hastayı çarpan cinlerin mağlup edildiği anlamına gelmektedir. Tuğ bağlamak iyi ruhları çağırmak, kötü ruhları cehenneme kovmak anlamına gelmektedir. Perihonluk, genellikle aşk derdinden sinir hastalığına yakalanmış kişiler veya aniden ruhunda değişiklik olan kişileri (çoğu zaman kadınlar) tedavi etmeyi amaçlar (Öger ve Gönel, 2011: 240-241).
} 
Bu sırada tefçiler komik ve hicvî unsurlar içeren halk koşaklarını söylerler (Davut ve Abliz, 2015: 270; Muhemmet, 2009: 253-254).

Yalğuz Kişilik Çélişiş (Tek Kişilik Güreş): Bu oyunda bir kişi meydana tek başına çıkıp güreşmeye başlar. Oyun süresince sanki karşısında güreştiği biri varmışçasına mücadele eder ve meşrep ehli onun kazanması için tezahürat eder. Oyun sonunda güreşçi rakibini yener. Bu oyun, Mekit nahiyesinin Yantek köyündeki meşreplerde oynanmaktadır (Davut ve Abliz, 2015: 285).

\section{Kikas}

“Kikas” kelimesi Uygur Türkçesinde "yaygara, gürültü” anlamına gelip (Necip, 2008: 234) Uygur Türklerinin çeşitli toplantı, merasim ve meşreplerinde çeşitli söz oyunları ve teatral sunumlar vasıtasıyla gülmeceyi ve eğlenceyi esas alan "kikasçılık" yapılmaktadır.

Özellikle Kumul bölgesi meşreplerinde önemli bir yere sahip olan kikasçıların, meşrep düzenini sağlamak, coşkuyu artırmak ve misafirlerin memnuniyetini ev sahibine iletmek gibi görevleri bulunmaktadır (İsmayil, 2007: 33-34). Bu yönüyle kikasçıların, kızıkçılara benzer bir misyona sahip olup aynı zamanda bahsi geçen toplantıların yönetiminden sorumlu olduğunu söylemek mümkündür. Kikasçılar, aynı zamanda bulundukları mecliste çeşitli sözlü kültür ürünlerinin icracısı olup genellikle mizahi ve satirik nitelikte beyitler söyleyerek katılımcıları eğlendirirler. Nitekim bu beyitler "kikas beyitleri" olarak adlandırılmaktadır:

Gelmeyenden gelen iyi,

Ağlayandan gülen iyi,

Meşrebe gelip sessizce oturandan

Seke seke oynayan iyi...

(O da) yoksa giden iyi.

Hey! Barekallahkikas!27 (İsmayil, 2007: 35).

\section{Sonuç}

Münferit olmaktan ziyade mensup olduğu toplumun değişkenlerine (din, dil, coğrafya, iklim... vb.) bağlı olarak nitelik kazanan mizah, tenkit etme, düşündürme, dikkat çekme, alay etme, üstünlük kurma, eğitme, eğlendirme ve güldürme gibi birçok işleve sahiptir. Uygur halk mizahı içerisinde de bu işlevleri yerine getiren birçok tür ve icracı bulunmaktadır.

Uygur halk latifeleri, güçlü hicvi karaktere sahip, kısa soluklu ve tek bir vaka ihtiva eden sözlü kültür ürünleri olup genellikle Nasreddin Hoca etrafında teşekkül etmesi sebebiyle halk arasında Ependi Latipiliri olarak bilinmektedir. Nitekim Türkçe konuşulan her bölgede halkın nüktedan bir kahramanı olan Nasreddin Hoca, Uygur Türkleri arasında da Ependi adıyla bilinen tipik bir halk sözcüsüdür.

Çakçaklar, insanları güldüren nükteli kısa sözlerden müteşekkil yapısıyla Uygur Türklerinin meşrep, seyle-baravet, toy ve dügün gibi toplu eğlence merasimlerinde, dinlenme ve eğlenme zamanlarında icra edilmektedir. Aynı zamanda bir eğitim kurumu mahiyetinde

${ }^{27}$ Kelmigendin kelginiñ yahşi,

Yiğliginindin külginiñ yaxşi,

Meşrepte kélip cim olturġandin

Sekrep sekrep oyniggniñ yaxşi...

Bolmisa ketkiniñ yaxşi.

He! Barekalla qiqas! 
olan bu meclislerde önemli çakçak ustaları yetişmektedir. Hisam Kurban, söz konusu ustalardan biri olup onun çakçaklarında Nasreddin Ependi, Seley Çakkan ve Molla Zeydin latifelerinde olduğu gibi sınıf çatışması ve zalim yöneticiler yer almamakta daha çok kendi biyografisinden ve gerçek yaşamdan hareketle mizahî temalar işlenmektedir.

Toplumsal meseleler, sınıf çatışması ve ideolojik kaygılar gibi her türlü toplumsal hassasiyet ve bireysel temaların işlendiği yumurlar, kara mizah ve kinayenin aynı paydada buluşturulduğu yapısıyla halkın sosyal gözlem gücü ve kıvrak zekâsının temsili mahiyetindedir.

Mübalağa ve gülme temelinde kurulan laflar, kısa hikâyeler olması bakımından çöçek, latife ve çakçak gibi diğer anlatmalık türlerin içerisinde de yer alabilmektedir.

Halk kızıkları, latifelere benzemekle birlikte kısa hacimli olup komik hareketler eşliğinde kızıkçılar tarafından icra edilmektedir. Nitekim kızıkçılar, eğlence meclislerinin, tören, merasim ve kutlamaların nahşa, ussul (halk dansı), müzik ve latifelerin vazgeçilmez icracıları arasındadır.

Kikas söyleme geleneği ve kikasçilar özellikle Kumul bölgesinde önemli bir yere sahiptir. Kikasçilar, kikas söyleme ve eğlendirme işlevlerinin yanı sıra toplu eğlence meclislerinin yönetim ve düzeninden de sorumludurlar.

Uygur halk mizahına genel olarak bakıldığında ele alınan aslî temanın sınıf çatışması ve adaletsiz yönetim anlayışı olduğunu söylemek mümkündür. Nitekim toplumun belleğinde yer alan bu sorunlara Nasreddin Ependi, Seley Çakkan, Molla Zeydin ve Hisam Kurban gibi temsili kişilikler ya da kızıkçı ve kikasçi gibi icracılar vasıtasıyla ete kemiğe büründürülerek dikkat çekilmektedir. Yine toplumsal meselelerin yanı sıra insan ilişkileri bağlamında önem taşıyan cimrilik, aptallık, küstahlık ve açgözlülük gibi hususlar da Uygur halk mizah türleri içerisinde ele alınarak gülmece vasıtasıyla tenkit edilmektedir. Bu noktada mizahın toplumun kıvrak zekâsının ürünü olan bir sanat eseri, mizahçının da toplumun sözcüsü olduğunu söylemek mümkündür.

\section{Kaynakça}

ABLIZ, Helimgül. (2009). Uygur Helk Meşrep Oyunliri Hekkide Tetkikat. Yayımlanmamış Yüksek Lisans Tezi, Şincan Üniversitesi.

BATU, Kaibinuer. (2018). Uygur Halk Mizahının Önemli Tipleri (Nesirdin Ependi, Seley Çakkan, Molla Zeydin, Hisam Kurban). Yayımlanmamış Yüksek Lisans Tezi, Akdeniz Üniversitesi Sosyal Bilimler Enstitüsü.

BERGSON, Henri. (2014). Gülüncün Anlamı Üzerine Deneme. (Çev.: Devrim Çetinkasap), İstanbul: Türkiye İş Bankası Kültür Yayınları.

DAVUT Rahile; MUHPUL, Yasin. (2011a). Uygur Meşrep Medeniyiti IV. Ürümçi: Şincan Güzel Senet-Foto Süret Neşriyatı.

DAVUT, Rahile; ABLIZZ, Helimgül. (2015). Uygur Meşrepliri Hekkide Omumiy Bayan. Ürümçi: Şincan Helk Neşriyati.

DAVUT, Rahile; MUHPUL, Yasin. (2011b). Uygur Meşrep Medeniyiti II. Ürümçi: Şincan Güzel Senet-Foto Süret Neşriyatı.

EBEY, Abdurahman, İMIN, Ehmet. (2006a). Uygur Halk Letipiliri. Ürümçi: Şincan Helk Neşriyati.

EBEY, Abdurahman, İMIN, Ehmet. (2006b) Uygur Halk Çakçakliri Hisam Çakçakliri. Ürümçi: Şincan Helk Neşriyati. 
EBEY, Abdurahman, İMIN, Ehmet. (2006c). Uygur Halk Lapliri. Ürümçi: Şincan Helk Neşriyati.

EMET, Erkin. (2013). Nüktedan Hisam Kurban. Ankara: Grafiker Yayınları.

GÉNİ, Buatikem. (2009). Uygurlarnn Nasirdin Ependi Letipiliri Hekkide Tetkikat. Yayımlanmamış Yüksek Lisans Tezi, Şincan Üniversitesi Halk Eğiz Edebiyati Bölümü.

GÖHERNISA, Muhemmetmusa. (2003). "Seley Çakkan Letipilirinin Milliy Alahidiliki Toğrisida". s. 68-70.

GÖNEL SÖNMEZ, Tugba. (2017). Uygur Meşrepleri Üzerine Bir İnceleme. Yayımlanmamış Doktora Tezi, Nevşehir Hacı Bektaş Veli Üniversitesi Sosyal Bilimler Enstitüsü.

GULAM, Ekber. (2006). Nasreddin Ependi LetipiliriKamusi I. Ürümçi: Şincan Yaşlar ÖsmürlerNeşriyati.

GÜVEMLİ, Zahir. (1949). Türk Mizah Edebiyatı Antolojisi. İstanbul: Varlık Yayınları.

HABİBULLA, Abdurehim. (2000). Uygur Etnografiyisi. Ürümçi: Şincan Halk Neşriyatı.

İNAYET, Alimcan. (1996). "Nasreddin Hoca ve Uygur Toplumu". Uluslararası Nasreddin Hoca Bilgi Şöleni Bildirileri. (Yayına Haz.: Alev Kahya Birgül), AKMB.

İNAYET, Alimcan. (2013). "Uygur Mizahında Çakçak ve Hésam Çakçakları, Türk Halk Edebiyatı İncelemeleri”, Saim Sakaoğlu Armağanı. (Ed.: Metin Ergun), Ankara: Türk Kültürünü Araştırma Enstitüsü.

İSMAYİL, Meryemgül. (2007). "Kumul Kikas Béyitliri Toğrisida”. Kumul Edebiyati 3.

İSMAYİL, Osman. (1994). Uygur Helk Eğiz Edebiyatidiki Janirlar. Ürümçi: Şincan YaşlarÖsmürlerNeşriyati.

KADİR, Ekber. (2011). Hisam Çakçakliri Hekkide. Pekin: Milletler Neşriyati.

KAŞGARLI, Sultan Mahmut (2008). Seley Çakkan Fıkraları. İstanbul: Çağrı Yayınları.

MORREALL, John. (1997). Gülmeyi Ciddiye Almak. (Çev.: Kubilay Aysevener ve Şenay Soyer), İstanbul: İris Yayınları.

Muhemmet Adil (2009) KaşkarUygur Dolan Medeniyeti. Kaşgar: Kaşgar Uygur Neşriyatı.

MUHEMMETMUSA, Göhernisa. (2003). "Seley Çakkan Letipilirinin Milliy Alahidiliki Toğrisida”. Hoten Pedegogika Aliy Téhnikomi İlmiy Jurnili, s. 2, 68-70.

NECIP, Emir Necipoviç. (2008). Yeni Uygur Türkçesi Sözlüğü.(Çev.:İklil Kurban), Ankara: Türk Dil Kurumu Yayınlarl.

OĞUZ, Şükran. (2015). "Seley Çakkan ve Molla Zeydin Şiirleri”. Uluslararası Uygur Araştırmaları Dergisi, S. 6, s. 95-105.

OĞUZ. M. Öcal. (2000). Türk Dünyası Halk Biliminde Yöntem Sorunları. Ankara: Akçağ Yayınları.

ÖGER, Adem; GÖNEL, Tugba. (2011). "Uygur Türkleri Arasında Şamanlar ve Tedavi Yöntemleri”. Turkish Studies, S. 6/4, s. 233-247.

ÖMER, Uçkuncan. (2013). Uygur Folklor Medeniyet Hezinisidin Ketriler. Ürümçi: Şincan Yaşlar Ösmürler Neşriyati.

ÖZKAN, İsa. (1992). "İki Uygur Fıkra Tipi: Molla Zeydin ve Seley Çakkan”. Milli Folklor, S. 16, s. $15-20$. 
RAHMAN, Abdukerim ve diğerleri. (1996). Uygur Örp Adetliri. Ürümçi: Şincan Yaşlar Ösmürler Neşriyati.

SAKAOĞLU, Saim. (1994-1995). "Türk Dünyası Mahallî Tipleriyle Anadolu Fıkra Tipleri Arasındaki Paralellikler". SÜ Fen Edebiyat Fakültesi Edebiyat Dergisi. S. 9-10,s. 267288.

TARİM, Osman İsmayil. (2009). Uygur Helk Eğiz Edebiyati Hekkide Umumiy Bayan. Ürümçi: Şincan Ünivérsitéti Neşriyati.

TURDİ, Ablikim. (1985). Helk Edebiyati Hekkide Omumiy Bayan, Urumçi: Şincan Helk Neşriyatı.

TÜRKÇE SÖZLÜK. (1998). Ankara: Türk Tarih Kurumu Basımevi.

UÇKUNCAN, Ömer. (2009). Uygur Halk Tarihi Koşakları Kamusu. Urumçi: Şincan Üniversitesi Neşriyatı.

UTUK, İmincan Ehmedi. (2006). Uygur Edebiyati Tarihi III. Pekin: Milletler Neşriyati.

UYGUR EDEBIYATİ TOĞRISIDA. (1982). (Ed.: Obul İslam), Pekin: Milletler Neşriyati.

UYĞUR TILINIIN IZAHLIK LUĞİTI “K-L”. (1994). Urumçi: Şincan Helk Neşriyatı.

UYĞUR TILINIÑ̃ IZAHLIK LUĞİTi “M-Ü”. (1995). Urumçi: Şincan Helk Neşriyatı.

UYĞUR TILINIIN IZZAHLIK LUĞITTI “T-H”. (1991).Urumçi: Şincan Helk Neşriyatı.

UYĞUR TILINIIN IZZAHLIK LUĞITII “ V-Y”. (1998). Urumçi: Şincan Helk Neşriyatı.

YALÇIN, Soner; EMET, Erkin. (1995). Nasrettin Hoca Uygurca-Türkçe. Ankara: Kültür Bakanlığı Yayınları.

ZEYIDİ, Mehmud; DUGAYLİ, Semet. (1988). Edebiyat AtalğuliriLuğiti. Pekin: Milletler Neşriyati.

\section{İnternet Kaynakları:}

* URL-1: Sopi, Nijat (2013). "Uygurların İli Çakçak (Şaka) Sanatı ve Çakçaklarda Yansıyan Kültürel Unsurlar Hakkında”. Çin Halk Cumhuriyeti İli Pedegojik Enstitüsü. https://www.academia.edu/4757838/UYGURLARIN_\%C4\%B0L\%C4\%B0_\%C3\%87AK\% C3\%87AK_\%C5\%9EAKA_SANATI_VE_\%C3\%87AK\%C3\%87AKLARDA_YANSIYAN_K\%C3 \%9CLT\%C3\%9CREL_UNSURLAR_HAKKINDA (Erişim: 20.04.2020) 